\title{
MODELING OF DRAFT AND ENERGY REQUIREMENTS OF A MOLDBOARD PLOW USING ARTIFICIAL NEURAL NETWORKS BASED ON TWO NOVEL VARIABLES
}

\author{
Abdulrahman Al-Janobi ${ }^{1}$, Saad Al-Hamed ${ }^{1}$, Abdulwahed Aboukarima ${ }^{1 *}$, Yousef Almajhadi ${ }^{1}$
}

${ }^{1 *}$ Corresponding author. King Saud University-College of Food and Agriculture Sciences/ Riyadh, Saudi Arabia.

E-mail: abasyouny@ksu.edu.sa | ORCID ID: https://orcid.org/0000-0002-2729-362X

\section{KEYWORDS}

soil texture index, field working index, artificial neural network, prediction, tillage.

\begin{abstract}
Draft and energy requirements are the most important factors in the activities of farm machinery management owing to their role in matching the tractor with implements for different tillage operations. This study's aim was to model the draft and energy requirements of a moldboard plow based on two novel variables. The first was the soil texture index (STI), which was formed from the clay, sand, and silt contents with a range of $0.03-0.84$. The second variable was the field working index (FWI), formed by combining the plow width, plowing speed, soil bulk density, soil moisture content, plowing depth, and tractor power into one dimensionless variable, which had a range of 7.17-82.45. The coefficient of determination $\left(\mathrm{R}^{2}\right)$ values obtained using a testing dataset were found out to be 0.9134 for energy and 0.8602 for draft requirements. For the draft and energy requirements of the testing data points, the mean absolute errors between the measured values and the values predicted using the artificial neural networks (ANN) model were $0.99 \mathrm{kN}$ and $2.39 \mathrm{~kW} \cdot \mathrm{h} / \mathrm{ha}$, respectively. Based on comparisons with other results reported using multiple linear regression, it was clear that the predictions by the proposed ANN model were very satisfactory.
\end{abstract}

\section{INTRODUCTION}

For crop planting, farmers usually prepare the soil using a primary tillage tool such as a moldboard plow (Abdallah et al., 2016). However, moldboard plowing ranks among the highest energy-consuming primary tillage operations (ASAE, 1992). The most appropriate way to estimate the energy requirements of a particular implement is to measure the draft required to pull it under the operating conditions, but it is prohibitively expensive to test a certain tillage tool under all conditions for every soil type (Grisso et al., 2012). Thus, draft requirement predictions of a definite tillage implement are an important research field. Many researchers have used various approaches for predicting draft force, including analytical, empirical, and numerical methods (Almaliki et al., 2018). However, the multiple linear regression (MLR) method is facile, as it can be used indirectly to estimate the draft and energy requirements of a tillage implement (Aboukarima, 2013; Almaliki et al., 2018) according to the available data and their quality.

Artificial neural networks (ANNs) are nonlinear computer algorithms that can model the behavior of complicated nonlinear processes. They can learn from history and experience and thereby enhance their efficiency (Tatar et al., 2016). The ANN model is more accurate than regression models and is flexible and easy to use (Noor et al., 2016). Moreover, the ANN method is a robust, powerful, and suitable technique for nonlinear and complex processes (Rajabi-Vandechali et al., 2018). ANNs have various advantages, such as the ability to handle a large amount of data, good globalization of results, the ability to implicitly separate nonlinear independent and nonindependent relationships, and the ability to determine the relative importance of different input parameters (Tu, 1996). However, they have many disadvantages, such as the black box, over fitting and under fitting problems of the network, and the experimental nature of model construction ( $\mathrm{Tu}, 1996)$.

The use of the ANN as an alternative to MLR for linking variables and parameters to physical and biological processes is increasing daily, and its effectiveness has been confirmed in agricultural applications. ANNs have been employed successfully in different applications in the field of farm machinery (Ajdadi \& Gilandeh, 2011; Al-Hamed et

${ }^{1}$ King Saud University-College of Food and Agriculture Sciences/ Riyadh, Saudi Arabia.

Area Editor: Renildo Luiz Mion

Received in: 3-10-2019

Accepted in: 4-22-2020 
al., 2013; Saleh \& Aly 2013; Taghavifar \& Mardani, 2013; Akbarnia et al., 2014; Almaliki et al., 2016; Karwasra et al., 2017; Borges et al., 2017; Rajabi-Vandechali et al., 2018; Shafaei et al., 2019).

Effectively selecting a combination of a tractor and a tillage implement is a complex task because it involves multiple parameters related to the soil, the machine or the settings, and the working conditions. Thus, the present study was based on the assumption that the ANN is a multidimensional nonlinear inference model with the ability to generalize or automatically derive rules from complex datasets. We aimed to develop an appropriate ANN model for estimating the draft and energy requirements of the moldboard plow during tillage operations according to the soil texture index (STI) and the field working index (FWI).

\section{MATERIAL AND METHODS}

ANN structure

ANNs comprise a large number of very simple interconnected processing elements called neurons. These neurons can be united to represent any relationship of inputs and outputs. They are used to solve a wide range of problems in science and engineering, particularly in areas where conventional modeling methods fail. The analytical facility of ANNs results from training on trial data and subsequent confirmation by independent data (Cirak \& Demirtas, 2014). A simple example of an artificial neuron is shown in Figure 1. Each neuron receives inputs $\boldsymbol{X}_{1}, \boldsymbol{X}_{2}, \ldots \boldsymbol{X}_{\boldsymbol{n}}$ attached to a weight $\boldsymbol{W}_{\boldsymbol{i n}_{\mathrm{n}}}$ that indicates the joining strength for a specific input for each connection (Ozgur et al., 2011).

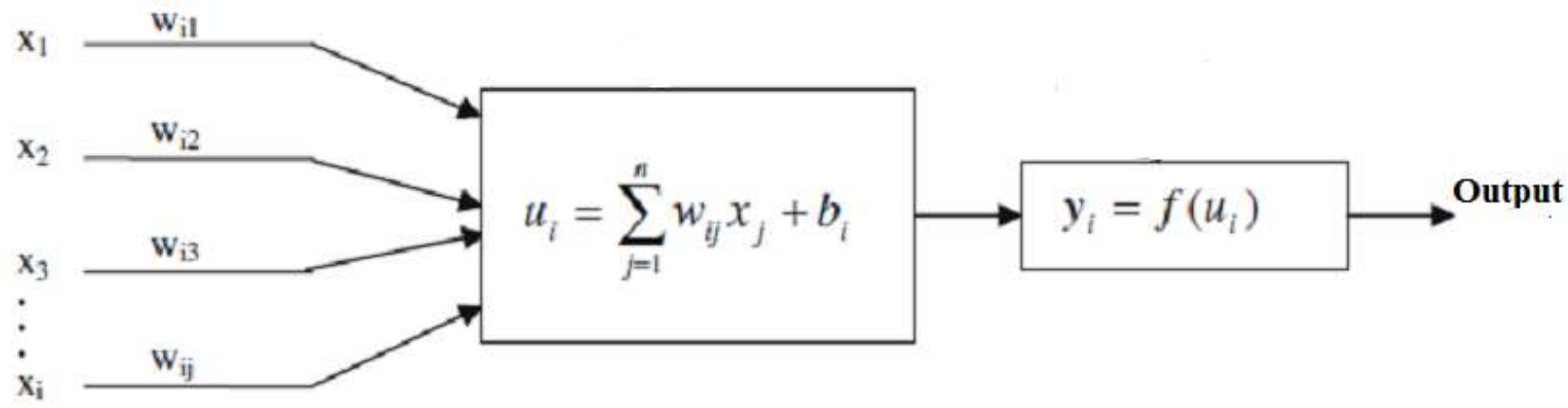

FIGURE 1. Style of neural computation (Cirak \& Demirtas, 2014).

Every input is then multiplied by the matching weight of the neuron connection. A bias $b_{i}$ can be considered as a type of connection weight with a constant nonzero value added to the summation of inputs and corresponding weights (Cirak \& Demirtas, 2014), as follows:

$$
u_{i}=\sum_{j=1}^{n} w_{i j} x_{j}+b_{i}
$$

The summation $u_{i}$ is moved using a scalar-to-scalar function called a transfer or activation function $f\left(u_{i}\right)$ to obtain a value called the unit activation, which is given as follows (Cirak \& Demirtas, 2014):

$$
y_{i}=f\left(u_{i}\right)
$$

Transfer functions allow nonlinearity to be introduced into neural networks, which makes the network more dominant than linear transformation. The backpropagation algorithm, which is the most commonly used training algorithm for the multilayer perceptron, minimizes the error for a specific training pattern (Eyercioglu et al., 2008). Accordingly, for a given input pattern, a flow of activation is forwarded from the input layer to the output layer via hidden layer(s). Then, the errors in the output are identified (Cirak \& Demirtas, 2014). The backpropagation algorithm is used to correct the weights by a small amount at a time, in a way that decreases the error. The training of the network is accomplished by changing the weights and biases. This procedure is implemented through a large number of training patterns and training iterations (Cirak \& Demirtas, 2014).

The aim of the learning procedure is to determine the optimal set of weights and biases that produce the correct output for any input. The output of the network is compared with the target response to produce an error. Once the ANN is properly trained, it can be generalized to similar situations that are unprecedented. Details regarding the ANN and its working principles are provided in the literature (Haykin, 1999). ANNs usually consist of an input layer, hidden layers, and an output layer. The multilayer perceptron is the best-known and most widely used type of ANN (Cirak \& Demirtas, 2014). A flowchart of the ANN modeling procedure is shown in Figure 2. 


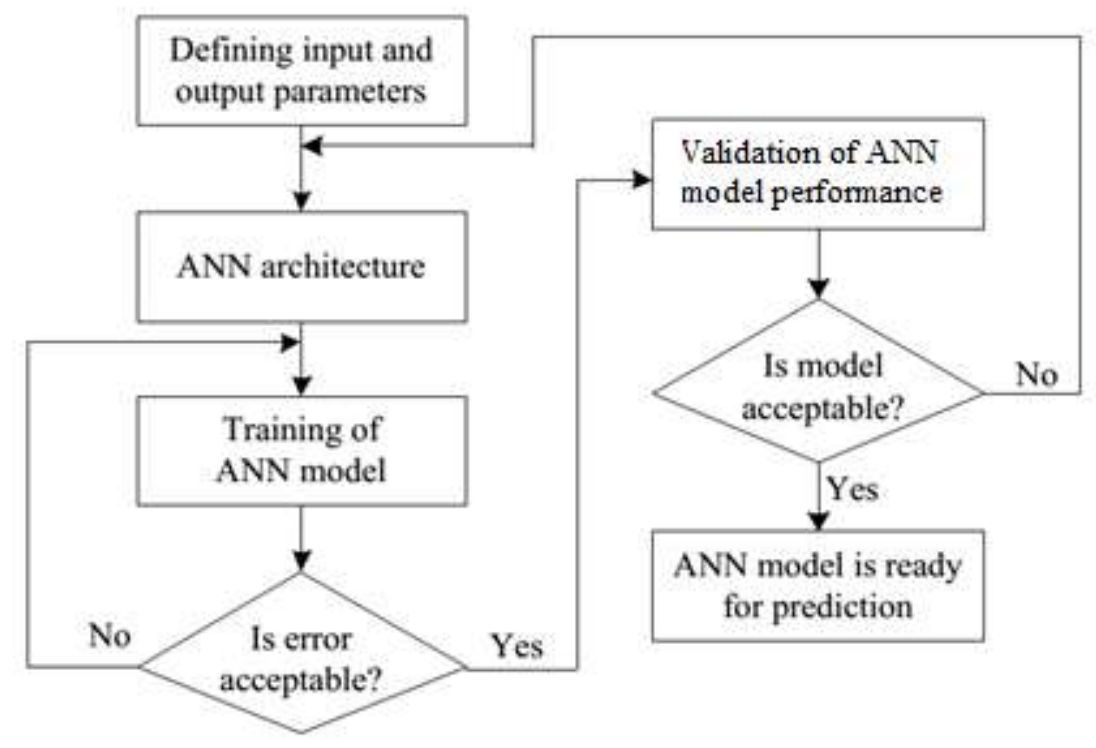

FIGURE 2. ANN modeling procedure flowchart (Noor et al., 2016).

\section{Data acquisition}

Numerous accurate and dependable parameters are of crucial importance in developing an intelligent model (Tatar et al., 2015). Hence, in this study, 189 data points covering a vast range of soil and working conditions were collected from the literature. The collected data were from field experiments and included the drafts of moldboard plows with various widths, plowing speeds, plowing depths, soil moisture contents, soil bulk densities, tractor powers, and different sand, clay, and silt contents in the soil. From these parameters, two novel variables were created. The first variable was (STI, dimensionless), which combines all the soil fractions and was represented by Oskoui \& Harvey (1992) as follows:

$$
S T I=\frac{\log \left(\mathrm{Ca}^{S i}+S a\right)}{100}
$$

Where:

$S a$ represents the sand content (\%) in the soil,

$\mathrm{Si}$ and $\mathrm{Ca}$ denote the percentages of silt and clay in the soil, respectively.

Oskoui \& Harvey (1992) demonstrated that the STI reflects the effects of all three soil fractions and differs for different combinations of sand, silt, and clay. The second variable was the FWI (dimensionless), which was defined as follows:

$$
\mathrm{FWI}=\frac{\mathrm{MC} \times \mathrm{P}}{\mathrm{BD} \times \mathrm{d}^{2} \times \mathrm{V} \times \mathrm{W}}
$$

Where:

$M C$ is the soil moisture content (decimal, $\mathrm{db}$ );

$P$ is the tractor power $(\mathrm{kW})$;

$B D$ is the soil bulk density $\left(\mathrm{kN} / \mathrm{m}^{3}\right)$;

$d$ is the plowing depth (m);

$V$ is the plowing speed $(\mathrm{m} / \mathrm{s})$, and

$W$ is the plow width (m).

The energy requirement (ER, $\mathrm{kW} \cdot \mathrm{h} / \mathrm{ha})$ was determined as follows:

$$
\begin{aligned}
& E R=\frac{H \times S}{3.6 \times T F C} \\
& T F C=\frac{W \times S}{10}
\end{aligned}
$$

Where:

$\mathrm{H}$ is the draft $(\mathrm{kN})$;

$\mathrm{S}$ is the plowing speed $(\mathrm{km} / \mathrm{h})$;

TFC is the theoretical field capacity (ha/h), and

3.6 and 10 are conversion factors.

Table 1 shows the minimum and maximum working parameters for the entire collected dataset. Moreover, the minimum and maximum of the input and output variables in the training and testing datasets for constructing the ANN and MLR models are depicted in Table 2. 
TABLE 1. Minimum and maximum working parameters for the entire collected dataset.

\begin{tabular}{|c|c|c|}
\hline Parameters & Minimum & Maximum \\
\hline Tractor power $(\mathrm{kW})$ & 45 & 104 \\
\hline Plow width (m) & 0.80 & 1.35 \\
\hline Plowing depth $(\mathrm{cm})$ & 7.20 & 22.00 \\
\hline Plowing speed $(\mathrm{km} / \mathrm{h})$ & 2.00 & 7.41 \\
\hline Sand (\%) & 11.40 & 29.98 \\
\hline Silt (\%) & 17.63 & 47.90 \\
\hline Clay (\%) & 29.80 & 53.32 \\
\hline Soil moisture content $(\%, \mathrm{db})$ & 14.80 & 25.60 \\
\hline Soil bulk density $\left(\mathrm{g} / \mathrm{cm}^{3}\right)$ & 1.08 & 1.52 \\
\hline
\end{tabular}

TABLE 2. Minimum and maximum of the input and output variables for constructing the ANN model.

\begin{tabular}{llcccc}
\hline \multirow{2}{*}{ Inputs } & \multirow{2}{*}{ Variables } & \multicolumn{2}{c}{ Minimum } & \multicolumn{2}{c}{ Maximum } \\
\cline { 2 - 5 } & STI & Training dataset & Testing dataset & Training dataset & Testing dataset \\
\cline { 2 - 5 } Outputs & FWI & 0.03 & 0.03 & 0.84 & 0.84 \\
& Draft $(\mathrm{kN})$ & 7.17 & 7.46 & 82.45 & 34.02 \\
& Energy $(\mathrm{kW} \cdot \mathrm{h} / \mathrm{ha})$ & 10.46 & 14.36 & 25.74 & 25.85 \\
\hline \multicolumn{2}{c}{ No. of observations } & 27.67 & 36.55 & 80.73 & 72.81 \\
\hline
\end{tabular}

\section{Field experiments for model verification}

Field experiments were conducted at the Agricultural Research and Experimental Farm in Dirab, Riyadh, Saudi Arabia. The longitude, latitude, and altitude of the experiment site were $46.65^{\circ} \mathrm{E}, 24.41^{\circ} \mathrm{N}$, and 575.79 $\mathrm{m}$, respectively. A block approximately $50 \mathrm{~m}$ long and $3 \mathrm{~m}$ wide was utilized in the experiments. A smaller block, approximately $10 \mathrm{~m}$ long and $3 \mathrm{~m}$ wide, at one end of each tested block, allowed the tractor and plow to reach a steadystate condition for the required plowing speed and plowing depth. The plowing depth was measured as the vertical distance from the top of the undisturbed soil surface to the deepest penetration point of the plow. In this study, the plowing depth was $10 \mathrm{~cm}$. The horizontal force (draft) was measured with a load cell (Omega model, with a capacity of $0-10,000 \mathrm{lb}$ ) using a previously reported method (FAO, 1994). The moldboard plow was hitched to a Fendt tractor (model 611LS, $70 \mathrm{~kW}$ ). The auxiliary tractor was a John Deere tractor (model 6615, $87 \mathrm{~kW}$ ). The draft was recorded within a distance of $40 \mathrm{~m}$. The plowing speed was calculated by measuring the distance covered by five turns of the tractor rear wheel with respect to time. In the same field, to record the idle draft force, the plow was lifted out of the ground, and the rear tractor was pulled. The difference between idle draft force and the loaded draft indicated the draft of the plow. A general-purpose moldboard with three bodies in the frame, each $360 \mathrm{~mm}$ wide (model 7073331, Overum-S, Sweden), was used in the experiment. Three plowing speeds, $2.7,3.4$, and $5.3 \mathrm{~km} / \mathrm{h}$ were achieved by changing the tractor gearbox gears. The soil contained $84.6 \%$ sand, $12.4 \%$ silt, and $3 \%$ clay. The soil bulk density was $1.42 \mathrm{~g} / \mathrm{cm}^{3}$ and the soil moisture content was $10.5 \% \mathrm{db}$.

\section{ANN model development}

To design the ANN model, the commercial neural network software, Qnet 2000 for Windows (Vesta Services,
2000), was used. The creation of an ANN must comprise the following steps: pattern definition, network implementation, identification of the learning parameters, training, and network testing. Qnet is a backpropagation neural modeling system that is designed to exploit the everincreasing power of computer hardware and operating systems. It can make predictions based on the artificial input vector set by the modeler (Ajagbe et al., 2013). The dataset contained 189 samples. The ANN used in this study had four layers: an input layer, two hidden layers, and an output layer. Prior to using the ANN model, the input and output values were normalized between 0.15 and 0.85 by the software, according to the following equation:

$$
T=\frac{\left(t-t_{\min }\right)}{\left(t_{\max }-t_{\min }\right)} \times(0.85-0.15)+0.15
$$

Where:

$t$ represents the original values of the input and output parameters;

$T$ is the normalized value, and

$t_{\max }$ and $t_{\min }$ are the maximum and minimum values, respectively, of the input and output parameters in the dataset.

The activated function was a sigmoid one owing to the good performance of sigmoid functions, which are generally used in feed forward neural network models (Shafaei et al., 2018). The dataset used for the model was divided into two categories, the training and testing sets. The software randomly selected 40 testing points.

The training mode was achieved by presenting the network with a set of data collected in a patterned form. Each training pattern included an input set of two parameters representing the STI and FWI and a set of 
outputs containing the draft and energy. In the training process, the network was presented with the variable in the input vector for the first training pattern, followed by an appropriate calculation through the nodes in the hidden layers and prediction of the desired output. The error between the target and predicted values was calculated and stored. The network was then presented with additional training patterns until it finished all the available data. Next, the root-mean-square error (RMSE) was calculated and backpropagated to the network. The biases and weights (connection strength) between nodes were adapted during the backpropagation stage to reduce the RMSE.

At the end of the training process, the neural network adopted was the one that gave the smallest RMSE with a good correlation. After several attempts of modifying the network topology and the numbers of neurons and hidden layers (data not shown), the resulting network had two neurons for the input layer, five and ten neurons for the two hidden layers, and two neurons for the output layer.

\section{Performance evaluation criteria}

By comparing the predictions with the measured values in the testing dataset, a model trained on the training set could be evaluated using multi-criteria approaches. These criteria included the RMSE and the mean absolute error (MAE) (Makridakis et al., 1998). Scatter plots were used for visual comparison of the observed and predicted values:

$$
\begin{aligned}
& R M S E=\sqrt{\frac{1}{n} \sum_{i=1}^{n}\left(P_{i}-O_{i}\right)^{2}} \\
& M A E=\frac{1}{n} \sum_{i=1}^{n}\left|P_{i}-O_{i}\right|
\end{aligned}
$$

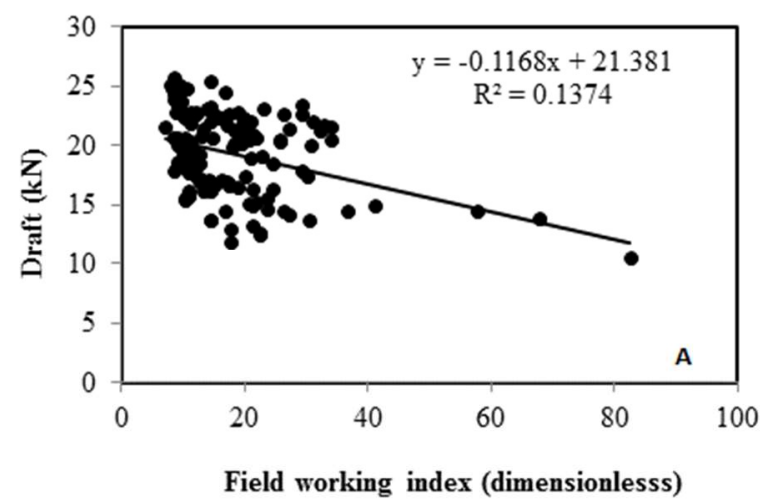

Where:

$P_{i}$ and $O_{i}$ are the predicted and observed values; respectively, and

$n$ is the total number of observations.

\section{RESULTS AND DISCUSSION}

\section{Data analysis}

The relationship between the FWI and the draft and energy requirements of the moldboard plow during tillage operation is depicted in Figure 3. Clearly, increasing the FWI decreased the draft and energy, with a low correlation. This is due to the nature of the data resources and the definition of the FWI, which was in the range of 7.17-82.45 for the training dataset. These results indicate that increasing the tillage depth, plowing speed, plow width, and soil bulk density decreased the FWI at a constant tractor power and soil moisture content, which affected the draft and energy demands. That is, the power required from the tractor to pull the moldboard plow increased with the tillage depth, plowing speed, plow width, and soil bulk density. These results confirm the findings of other researchers (AlSuhaibani \& Al-Janobi, 1997; Zwilling \& Hummel, 1988). Moreover, the tillage implement energy is directly related to the working depth, tool geometry, travel speed, width of the implement, and soil properties (Gill \& Van den Berg, 1968; Palmer \& Kruger, 1982). The soil properties that affect tillage energy are moisture content, bulk density, cone index, and soil texture (Upadhyaya et al., 1984).

For the FWI formulation, increasing the soil moisture content and tractor power at a constant of plowing depth, plow width, plowing speed, and soil bulk density resulted in an increase of the draft and energy. However, Ahmed (2006) measured the draft using two tractor powers of 60 and 67.5 $\mathrm{kW}$ and found that the draft of a disk plow in clay soil was 11.72 and $12 \mathrm{kN}$ when the tractor power was 60 and $67.5 \mathrm{~kW}$, respectively, with the other parameters constant.

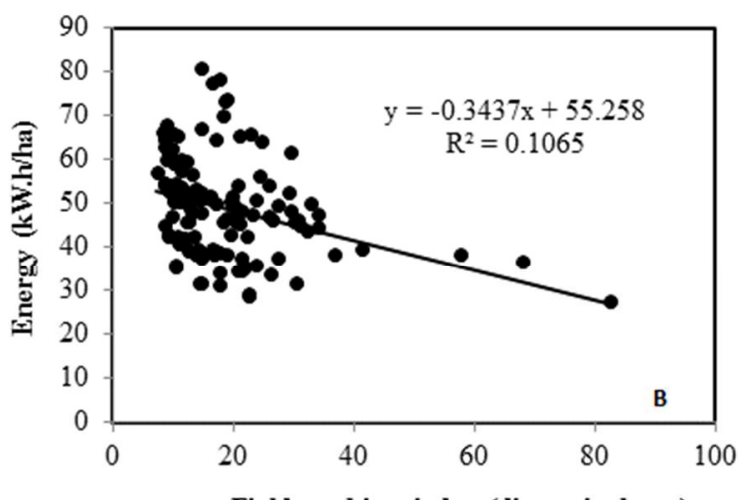

Field working index (dimensionlesss)

FIGURE 3. Relationship between the field working index and the draft and energy requirements of the moldboard plow during tillage operation.

Figure 4 depicts the relationship between the STI and the draft and energy requirements of the moldboard plow during tillage operation. Clearly, increasing the STI increased the draft and energy, with a low correlation. The STI was in the range of $0.03-0.84$, and the clay content of the soils in the collected data was dominant; thus, a clear effect of STI was observed. However, Ahmed (2006) measured the draft in two soils, clay soil with an STI of
0.586 and sandy clay soil with an STI of 0.403 , and found the draft of a disk plow to be 11.72 and $11.61 \mathrm{kN}$ in soil having an STI of 0.586 and 0.403 , respectively. He concluded that the average draft in clay soil was $4.72 \%$ greater than that in sandy clay soil. Abbaspour-Gilandeh et al. (2006) evaluated the energy requirements of conventional tillage with respect to tractor speed and soil parameters. They concluded that soil electrical-conductivity 
data were positively correlated to soil texture, and there was a strong linear positive correlation between soil electrical conductivity and the draft force across the field. Additionally, they tested tillage implements in different soil textures: Faceville, which is in the family of clayey-kaolinitic; thermic, Typic Paleudults, and Fuquay, which are in the family of loamy-siliceous-thermic; Arenic Plinthic Paleudults and Lakeland, which are in the family of siliceous-thermic-coated; and Typic Quartzipsammentsthe. These soils had calculated STIs of $0.039,0.067$, and 0.120 . The highest draft was observed at an STI of 0.120 , and the lowest draft was observed at an STI of 0.039, at different

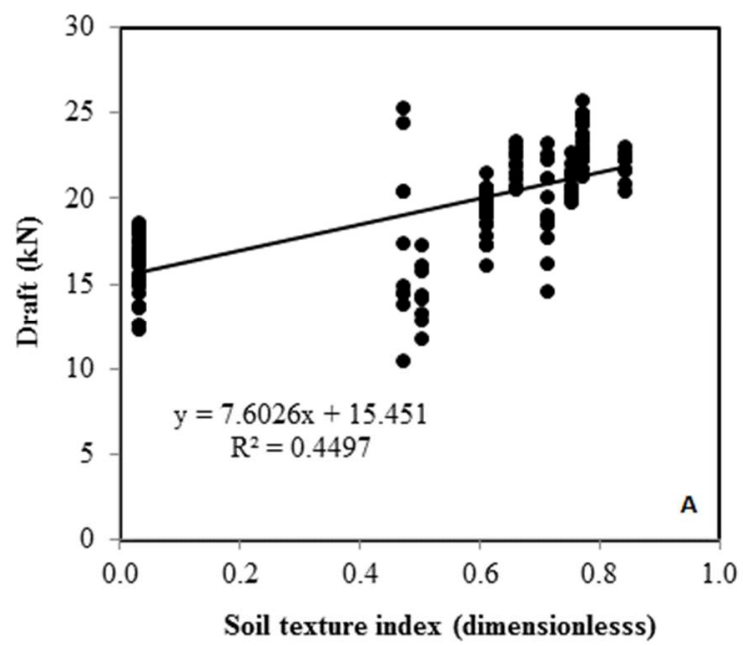

speeds. Thus, the STI in the present study was available for vast types of soil, and it is important to correlate this index with the draft and energy demands of tillage implements because there is presently a shortage of data on the draft and power demands of agricultural tillage implements operating in different soils (Okoko et al., 2018). However, soil-related parameters, such as the soil texture and organic-matter content, influence the draft in soil tillage (McLaughlin et al., 2002). Kirisci (1994) reported draft values of 9.481 and $18.717 \mathrm{kN}$ for a moldboard plow operating in soils having a sandy loam texture and a clay texture, respectively, at plowing depths of 14.7 and $14.4 \mathrm{~cm}$, respectively.

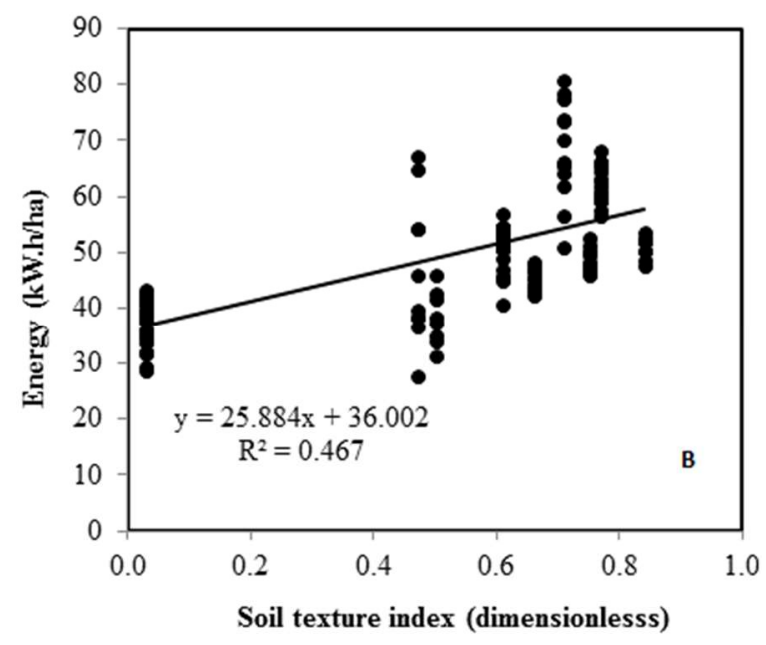

FIGURE 4. Relationship between the soil texture index and the draft and energy requirements of the moldboard plow during tillage operation.

\section{Analysis of performance of the ANN model}

One of the major objectives of this study was to compare the predicted and observed values for the draft and energy. A difference between the observed and predicted variables was expected and inevitable (Kirisci, 1994). If the predicted value is higher than the observed value, this is called over prediction. If it is lower, this is called under prediction. Both cases are described as prediction errors. In this study, the draft and energy requirements of the moldboard plow during tillage operation were predicted using the ANN backpropagation model. This method considers the combinations of the tractor, machine, and soil characteristics as one model. The ASABE (ASAE, 1992) model for the moldboard plow gives a global figure for the draft of the implement; thus, it cannot be used for specific sites and implements (Kirisci, 1994). Thus, in this study, the best architecture of the ANN model was constructed as a 2-5-10-2 architecture for the prediction of variables. The criteria of the RMSE, MAE, and $\mathrm{R}^{2}$ were selected to evaluate the networks with the optimum solution. A regression analysis between the network output and the corresponding targets was performed in order to investigate the network response in detail. The results showed that the constructed model was sufficient for predicting the draft and energy requirements of the moldboard plow during tillage operation at various STIs and FWIs. Figure 5 shows a plot of the observed and ANN-predicted values for the draft and energy requirements in the case of the testing dataset. A good correlation between the observed and ANNpredicted values is observed, as indicated by the high values of $\mathrm{R}^{2}$ ( 0.9134 for energy and 0.8602 for draft). $R^{2}$ can be interpreted as the proportion of the variation in the predicted values that is explained by the variation in the observed values. The $\mathrm{R}^{2}$ value is one if the observed and predicted values all lie on a straight line, so that the residuals are zero. In Figure 5, the distribution of the data points predicted by the ANN model is very close to the observed data. The ANN model gives the best fit to the observed results and produces the best prediction of the draft and energy requirements during tillage operation compared to MLR. 

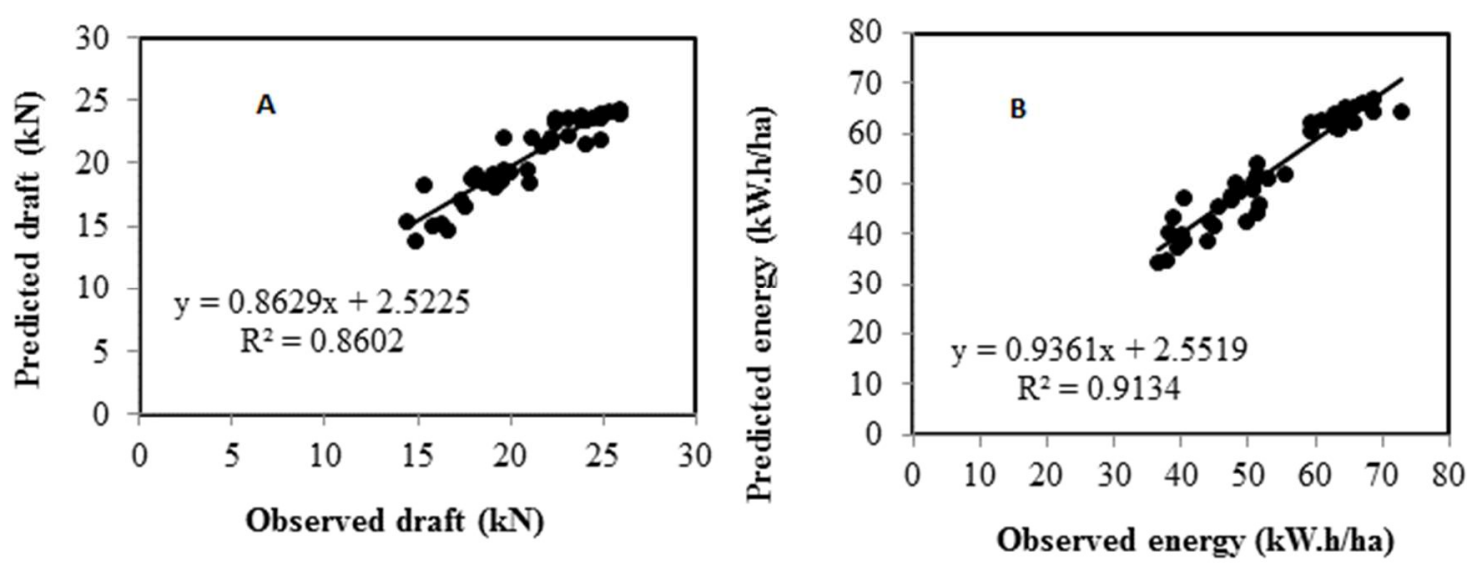

FIGURE 5. Relationships between the observed and predicted data for the (A) draft and (B) energy of the ANN model in the case of the testing dataset.

\section{Analysis of performance of the MLR model}

MLR models have been developed to predict the relationship between the input parameters and the draft and energy requirements. The multiple regression technique is used to determine the relationship among variables. This is a linear statistical technique that is used for establishing the best relationship between variables using the least-squares method. Multiple regressions take the following form:

$$
Y=a+b_{1} X_{1}+b_{2} X_{2}+b_{3} X_{3} \ldots \ldots+b_{k} X_{k}
$$

Where:

$Y$ is the dependent variable to be predicted;

$X_{1}, X_{2}, X_{3}, \ldots, X_{k}$ are the $k$ known variables on the basis of which the predictions are to be made, while $a, b_{1}, b_{2}, b_{3}, \ldots, b_{k}$ are the coefficients.

An Excel spreadsheet was used to calculate the values of the coefficients for different responses. The ANN training dataset was used as training data for the MLR model. The performance of the MLR models was assessed using regression analysis. Figure 6 compares the predicted values from the MLR models and the observed values. The prediction equations that resulted from the trained MLR model are as follows:

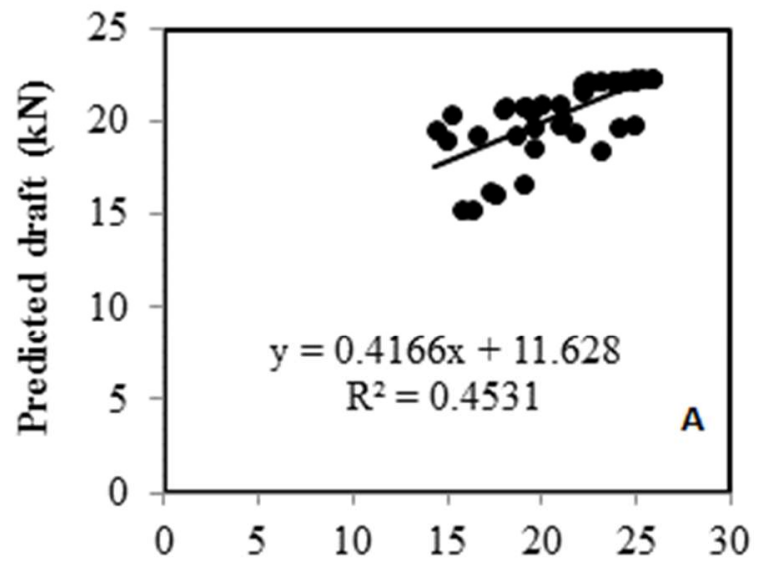

\section{Observed draft $(\mathrm{kN})$}

$\operatorname{Draft}(\mathrm{kN})=17.45808+7.576786 \times \mathrm{STI}-0.11552 \times$ FWI

$\mathrm{R}^{2}=0.584$

Energy $(\mathrm{kW} \cdot \mathrm{h} / \mathrm{ha})=41.89618+25.80786 \times \mathrm{STI}-0.33926 \times \mathrm{FWI}$ $\mathrm{R}^{2}=0.571$

The efficiency and predictability of the developed ANN and MLR models were measured according to the statistical criteria of the RMSE and MAE. Table 3 shows that the MAE for the ANN model was smaller than that for the MLR model. For the draft requirements, the ANN and MLR models had MAEs of 0.99 and $2 \mathrm{kN}$, respectively. For the energy requirements, the ANN and MLR models had MAEs of 2.39 and $5.40 \mathrm{~kW} \cdot \mathrm{h} / \mathrm{ha}$, respectively. Thus, the ANN model produced more accurate results than the MLR model. Furthermore, with the MLR model, it is difficult to determine the relationships between the process parameters and the draft and energy requirements, because they are complex and nonlinear. Thus, the neural network model is superior in predicting the draft and energy with high precision owing to its high robustness and accuracy.

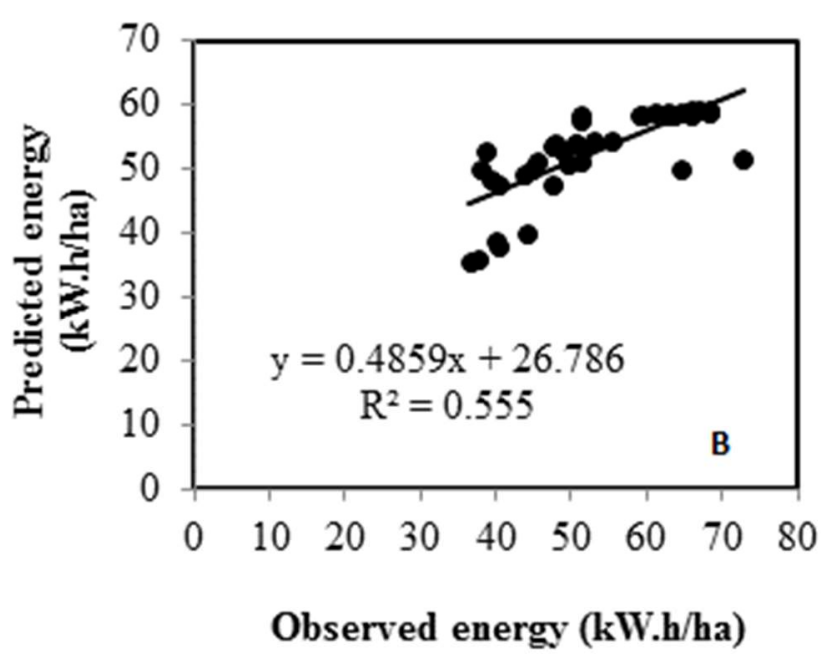

FIGURE 6. Relationships between the observed and predicted data for the (A) draft and (B) energy of the MLR model in the case of the testing dataset. 
TABLE 3. Error criteria of the developed models for prediction of the draft and energy requirements during tillage operation in the case of the testing dataset.

\begin{tabular}{cccc}
\hline Model type & Variable & RMSE & MAE \\
\hline ANN & Draft $(\mathrm{kN})$ & 1.27 & 0.99 \\
ANN & Energy $(\mathrm{kW} \cdot \mathrm{h} / \mathrm{ha})$ & 3.15 & 2.39 \\
MLR & Draft $(\mathrm{kN})$ & 2.49 & 2.00 \\
MLR & Energy $(\mathrm{kW} \cdot \mathrm{h} / \mathrm{ha})$ & 6.95 & 5.40 \\
\hline
\end{tabular}

\section{Quantifying relative contribution}

An important feature of the program Qnet is that it allows quantification of the relative contribution of each input neuron to the computed output value. Hence, it is possible to identify the most relevant factors affecting the draft and energy demands of the tillage implement. The individual contributions of the inputs are shown in Figure 7. The STI made average contributions of $49.45 \% \%$ and $41.58 \%$ in the cases of draft and energy, respectively. The FWI made average contributions of $50.55 \%$ and $58.42 \%$ for draft and energy, respectively.

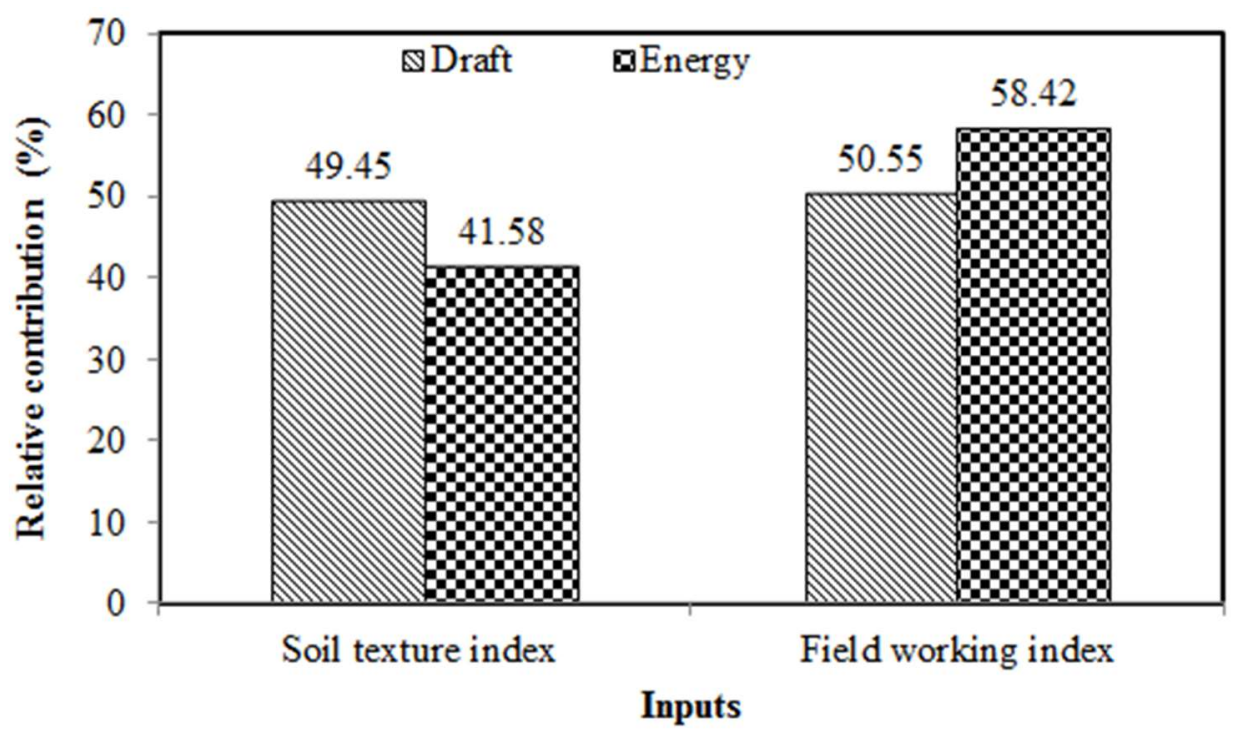

FIGURE 7. Relative contribution percentages of the input parameters to the output.

\section{Analysis of validation dataset}

In the validation process, the calculated STI for the soil in the field experiment was 0.03 , and the calculated FWI was in the range of 41.24-80.96, which were within the training data range. The measured and predicted draft and energy requirements are presented in Table 4. Clearly, the ANN-predicted draft was higher than the measured values, except at an FWI of 80.96 , and the same trend was observed for the MLR model. The predicted energy was lower than the measured values for both the ANN and MLR models at FWIs of 80.96 and 64.29 , respectively, as depicted in Table 4. The average percentage error (PE) between the predicted and measured variables was computed. The PE (\%) was calculated using the following equation (Kirisci, 1994):

$$
P E=\left(\frac{P i-O i}{O i}\right) * 100
$$

TABLE 4. Measured and predicted draft and energy requirements corresponding to the STI and FWI for validation data.

\begin{tabular}{|c|c|c|c|c|c|c|c|}
\hline \multicolumn{4}{|c|}{ Predicted } & \multicolumn{2}{|c|}{ Measured } & \multicolumn{2}{|c|}{ Inputs } \\
\hline \multicolumn{2}{|c|}{ Energy $(\mathrm{kW} \cdot \mathrm{h} / \mathrm{ha})$} & \multicolumn{2}{|c|}{ Draft $(\mathrm{kN})$} & \multirow{2}{*}{$\begin{array}{c}\text { Energy } \\
(\mathrm{kW} \cdot \mathrm{h} / \mathrm{ha})\end{array}$} & \multirow{2}{*}{$\begin{array}{l}\text { Draft } \\
(\mathrm{kN})\end{array}$} & \multirow{2}{*}{$\frac{\text { FWI }}{(---)}$} & \multirow{2}{*}{$\frac{\text { STI }}{(---)}$} \\
\hline ANN & MLR & ANN & MLR & & & & \\
\hline 15.20 & 18.20 & 8.33 & 8.13 & 21.86 & 8.50 & 80.96 & 0.03 \\
\hline 20.86 & 23.16 & 10.26 & 10.02 & 24.69 & 9.60 & 64.29 & 0.03 \\
\hline 28.68 & 28.15 & 12.92 & 11.74 & 27.78 & 10.80 & 41.24 & 0.03 \\
\hline
\end{tabular}


For draft, the average PEs were $2.91 \%$ and $8.18 \%$ when the ANN and MLR models were applied, respectively. For energy, the average PEs were $-7.20 \%$ and $-14.24 \%$ when the ANN and MLR models were applied, respectively. If a model predicts the draft requirements of the tillage implements within a PE of $\pm 20 \%$, it is considered acceptable (Kirisci, 1994). Figure 8 shows the relationships between the measured data for draft and the data predicted

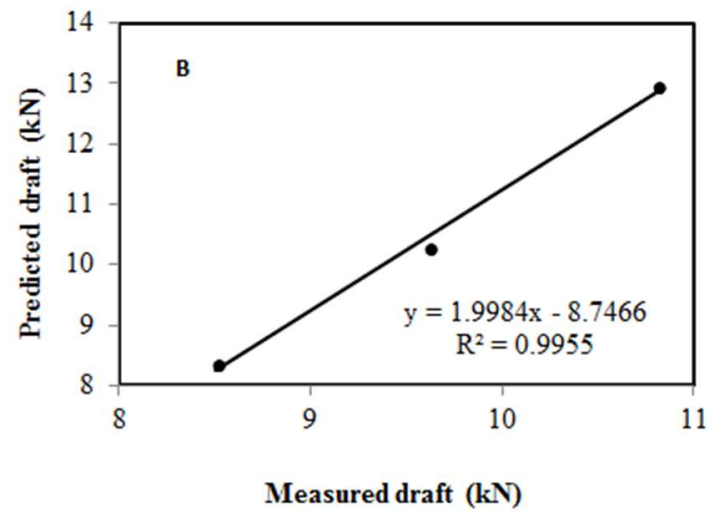

using the ANN and MLR models with the validation dataset. Figure 9 shows the relationships between the measured data for energy and the data predicted using the ANN and MLR models with the validation dataset. The MLR models had the best fit for the validation dataset compared to the ANN model; thus, the two MLR equations for the draft and energy can be utilized in a simulation of the draft and energy requirements of a moldboard plow during tillage operation.

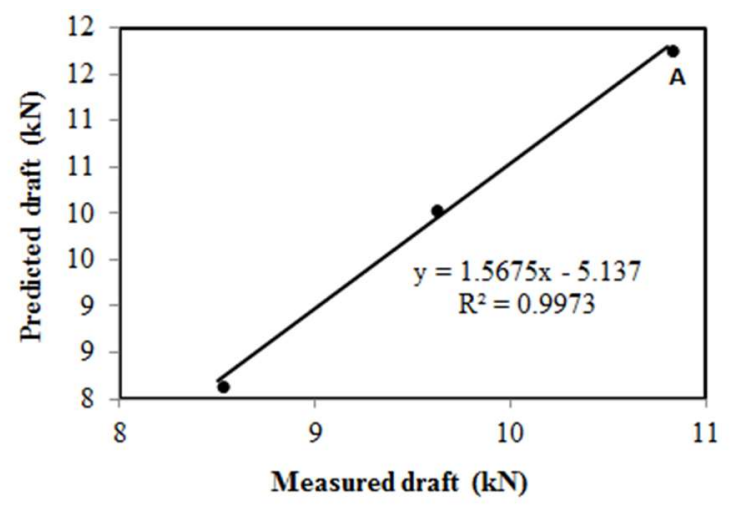

FIGURE 8. Relationships between the measured data for draft and the data predicted by the (A) ANN and (B) MLR models using the validation dataset.
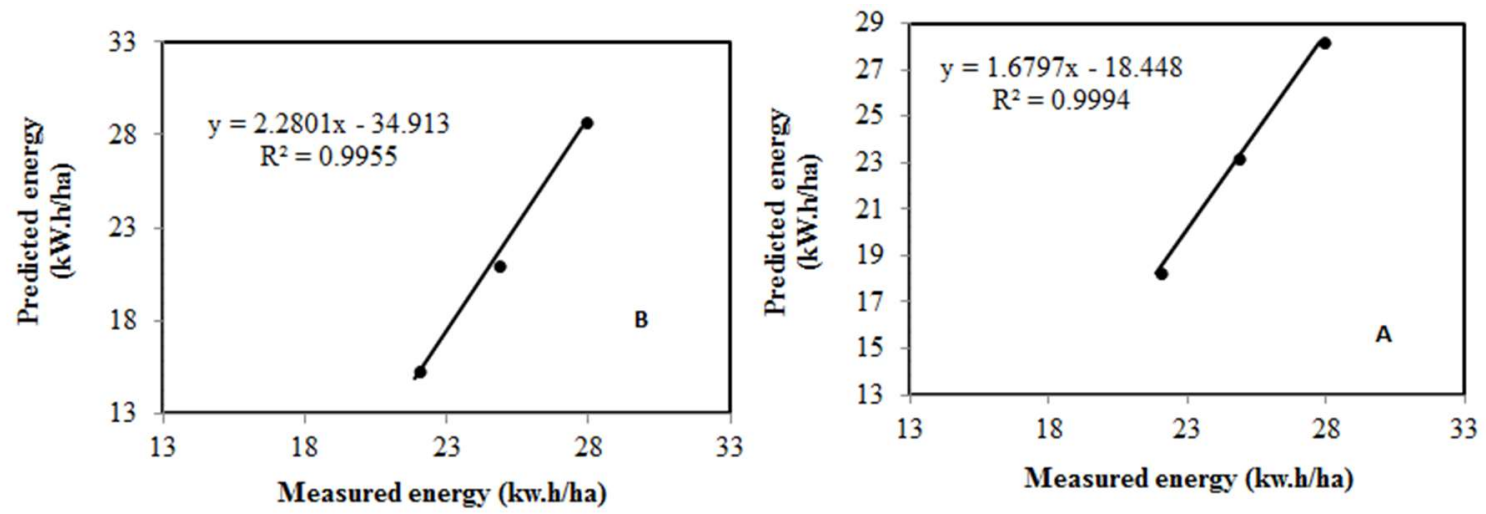

FIGURE 9. Relationships between the measured data for energy and the data predicted by the (A) ANN and (B) MLR models using the validation dataset.

\section{CONCLUSIONS}

Two variables, the STI and FWI, were developed as input parameters in an ANN model to predict the draft and energy requirements of a moldboard plow during tillage operations. The developed ANN model had two neurons for the input layer, five and ten neurons for the two hidden layers, and two neurons for the output layer (2-5-10-2). The results showed that the training algorithm of standard backpropagation was sufficient for predicting the draft and energy requirements. The potential of the MLR model and the ANN model for prediction was assessed. For draft, the RMSEs of the ANN and MLR models were 1.27 and 2.49 $\mathrm{kN}$, respectively, and for energy, they were 3.15 and 6.95 $\mathrm{kW} \cdot \mathrm{h} / \mathrm{ha}$, respectively. The ANN model is a powerful tool that is easy to use for nonlinear problems. The developed ANN model can be reliably used for the accurate prediction of the draft and energy requirements of a moldboard plow during tillage operations over a vast range of STIs (0.030.84 ) and FWIs (7.17-82.45).

\section{ACKNOWLEDGMENTS}

With respect and gratitude, the authors thank the Deanship of Scientific Research, Researchers Support Services Unit and Agricultural Research Center, College of Food and Agriculture Sciences at the King Saud University for their technical support and encouragement.

\section{REFERENCES}

Abbaspour-Gilandeh Y, Alimardani R, Khalilian A, Keyhani A, Sadati H (2006) Energy requirement of sitespecific and conventional tillage as affected by tractor speed and soil parameters. International Journal of Agriculture \& Biology 8(4): 499-503.

Abdallah FE, Ding W, Ding Q, Pan G (2016) Design, development, and performance evaluation of a trash-board moldboard plow for the interaction between soil and straw with two different water content levels. Agronomy 6(30):112. DOI: http://dx.doi.org/10.3390/agronomy 6020030 
Aboukarima AM (2013) Evaluation of using a combination of simulated and experimental data to predict draft force of a moldboard plow. Misr Journal of Agricultural Engineering 30 (1):1-28.

Ahmed EAH (2006) Tillage implements performance as affected by tractor power and forward speed. MSc. Thesis, Khartoum. University of Khartoum, Faculty of Agriculture.

Ajagbe WO, Ganiyu AA, Owoyele MO, Labiran JO (2013) Modeling the effect of crude oil impacted sand on the properties of concrete using artificial neural networks. International Scholarly Research Notices Civil Engineering 2013(ID 609379):1-5. DOI: http://dx.doi.org/10.1155/2013/609379

Ajdadi FR, Gilandeh YA (2011) Artificial neural network and stepwise multiple range regression methods for prediction of tractor fuel consumption. Measurement 44(10):2104-2111. DOI:

http://dx.doi.org/10.1016/j.measurement.2011.08.006.

Akbarnia A, Mohammadi A, Farhani F, Alimardani R (2014) Simulation of draft force of winged share tillage tool using artificial neural network mode. Agricultural Engineering International: CIGR Journal 16:57-65.

Al-Hamed SA, Wahby MF, Al-Saqer SM, Aboukarima AM, Sayedahmed AA (2013) Artificial neural network model for predicting draft and energy requirements of disk plow. Journal of Animal \& Plant Sciences 23(6):1714-1724.

Almaliki S, Alimardani R, Omid M (2016) Artificial neural network based modeling of tractor performance at different field conditions. Agricultural Engineering International: CIGR Journal 18(4): 262-274.

Almaliki S, Himoud MS, Muhsin SJ (2018) A stepwise regression algorithm for prognostication draft requirements of disk plough. In: International Conference on Promotion of Scientific \& Regional Cooperation on Food and Agricultural Sciences, Mashhad.

Al-Suhaibani SA, Al-Janobi AA (1997) Draught requirements of tillage implements operating on sandy loam soil. Journal of Agricultural Engineering Research 663:177-182. DOI:

http://dx.doi.org/10.1006/jaer.1996.0130

ASAE (1992) D497 Agricultural machinery data - Draft and power requirements. In: ASAE Standards, p 293-299.

Borges PHM, Mendoza ZMSH, Maia JCS, Bianchini A, Fernándes HC (2017) Estimation of fuel consumption in agricultural mechanized operations using artificial neural networks. Engenharia Agrícola 37(1):136-147. DOI:

http://dx.doi.org/10.1590/1809-4430-

eng.agric.v37n1p136-147/2017

Cirak B, Demirtas S (2014) An application of artificial neural network for predicting engine torque in a biodiesel engine. American Journal of Energy Research 2(4):74-80. DOI: http://dx.doi.org/10.12691/ajer-2-4-1
Eyercioglu O, Kanca E, Pala M, Ozbay E (2008)

Prediction of martensite and austenite start temperatures of the Fe-based shape memory alloys by artificial neural networks. Journal of Materials Processing Technology 200:146-152. DOI:

http://dx.doi.org/10.1016/j.jmatprotec.2007.09.085

FAO (1994) Testing and evaluation of agricultural machinery and equipment: principles and practices. FAO, Agric. Serv. Bull. 110. Available: http://www.fao.org/3/at1841e.pdf. Accessed: Dec 14, 2018.

Gill WR, Van den Berg GF (1968) Soil dynamics in tillage and traction. Washington, USDA Agricultural Research. 316. Available:

https://naldc.nal.usda.gov/download/CAT10309639/PDF. Accessed: Dec 14, 2018).

Grisso RD, Ehrhardt JP, Kocher MF, Jasa PJ, Schinstock JL (2012) Using the Veris electrical conductivity cart as a draft predictor. Poljoprivredna Tehnika 3:45-61.

Haykin S (1999) Neural networks, a comprehensive foundation. Prentice Hall, $2^{\text {nd }}$ ed. 235p.

Karwasra N, Kumar A, Kalra A, Mukesh S, Rani V, Sarita $S$ (2017) Tractor drawbar performance prediction using artificial neural network. Journal of Agricultural Engineering 54(2):1-9.

Kirisci V (1994) A field method for predicting the draught forces of the tillage implements. PhD Dissertation, Silso, Agricultural and Environmental Engineering.

Makridakis S, Wheelwright SC, Hyndman RJ (1998) Forecasting: methods and applications. New York, John Wiley $\&$ Sons, $3^{\text {rd }}$ ed. 642 p.

McLaughlin NB, Gregorich EG, Dwyer LM, Ma BL (2002) Effect of organic and inorganic soil nitrogen amendments on mouldboard plow draft. Soil and Tillage Research 64(3-4):211-219. DOI: http://dx.doi.org/10.1016/S0167-1987(01)00270-7

Noor CWM, Mamat R, Najafi G, Yasin MHM, Ihsan CK, Noor MM (2016) Prediction of marine diesel engine performance by using artificial neural network model. Journal of Mechanical Engineering and Sciences (JMES) 10:1917-1930. DOI:

http://dx.doi.org/10.15282/jmes.10.1.2016.15.0183

Okoko P, Ajav EA, Olosunde WA (2018) Draft and power requirements for some tillage implements operating in clay loam soil. Agricultural Engineering International: CIGR Journal 20(1):95-102.

Oskoui KE, Harvey SJ (1992) Predicting cone index from soil physical properties and organic matter content. St. Joseph, ASAE, p1-6. ASAE paper n. 92-1056.

Ozgur T, Tuccar G, Ozcanli M, Aydin K (2011) Prediction of emissions of a diesel engine fueled with soybean biodiesel using artificial neural networks. Energy Education Science and Technology Part A: Energy Science and Research 27:301-312.

Palmer AL, Kruger IR (1982) Comparative drafts of six tillage implements. Conference on Agricultural Engineering. Armidale, NSW Australia, Proceedings... 
Rajabi-Vandechali M, Abbaspour-Fard MH, Rohani A (2018) Development of a prediction model for estimating tractor engine torque based on soft computing and low cost sensors. Measurement 121:83-95. DOI:

http://dx.doi.org/10.1016/j.measurement.2018.02.050

Saleh B, Aly AA (2013) Artificial neural network model for evaluation of the ploughing process performance. International Journal of Control, Automation and Systems 2(2):1-11.

Shafaei SM, Loghavi M, Kamgar S (2018) A comparative study between mathematical models and the ANN data mining technique in draft force prediction of disk plow implement in clay loam soil. Agricultural Engineering International: CIGR Journal 20(2):71-79.

Shafaei SM, Loghavi M, Kamgar S (2019) Prognostication of energy indices of tractor-implement utilizing soft computing techniques. Information Processing in Agriculture 6(1):132-149. DOI:

http://dx.doi.org/10.1016/j.inpa.2018.08.001

Taghavifar H, Mardani A (2013) Application of artificial neural networks for the prediction of traction performance parameters. Journal of the Saudi Society of Agricultural Sciences 13(1):35-43. DOI: http://dx.doi.org/10.1016/j.jssas.2013.01.002.
Tatar A, Naseri S, Sirach N, Lee M, Bahadori A (2015) Prediction of reservoir brine properties using radial basis function (RBF) neural network. Petroleum 1:349-357. doi: http://dx.doi.org/10.1016/j.petlm.2015.10.011

Tatar A, Najafi-Marghmaleki A, Barati-Harooni A, Gholami A, Ansari HR, Bahadori M, Kashiwao T, Lee M, Bahadori A (2016) Implementing radial basis function neural networks for prediction of saturation pressure of crude oils. Petroleum Science and Technology 34(5):454-463. DOI: http://dx.doi.org/10.1080/10916466.2016.1141217

Tu JV (1996) Advantages and disadvantages of using artificial neural networks versus logistic regression for predicting medical outcomes. Journal of Clinical Epidemiology 49(11):1225-1231. DOI: http://dx.doi.org/10.1016/S0895-4356(96)00002-9

Upadhyaya SK, Williams TH, Kemble LJ, Collins NE (1984) Energy requirement for chiseling in coastal plain soils. Transaction of ASAE 36(5):1267-1270. DOI: http://dx.doi.org/10.13031/2013.33019

Vesta Services (2000) Qnet2000 Shareware, Vesta Services, 1001 Green Bay Rd, STE 196, Winnetka, IL 60093.

Zwilling EL, Hummel JW (1988) Draft and energy requirements for Midwest tillage operations. St. Joseph, ASAE. ASAE paper n. 88-1115. 